\title{
Pulmonary arterial hypertension in the elderly: Clinical perspectives
}

\author{
Nicholas Rothbard ${ }^{1}$, Abhinav Agrawal $^{2}$, Conrad Fischer ${ }^{1,3}$, \\ Arunabh Talwar ${ }^{2}$, Sonu Sahni ${ }^{1,3}$ \\ ${ }^{1}$ Department of Primary Care, Touro College of Osteopathic Medicine, New York, NY, USA \\ ${ }^{2}$ Department of Pulmonary, Northwell Health System, \\ Critical Care and Sleep Medicine, New Hyde Park, NY, USA \\ ${ }^{3}$ Department of Medicine, Brookdale University Hospital Medical Center, Brooklyn, NY, USA
}

\begin{abstract}
Pulmonary hypertension $(\mathrm{PH})$ is a rare and devastating disease characterized by progressive increases in pulmonary arterial pressure and pulmonary vascular resistance, which eventually leads to right ventricular failure and death. Pulmonary arterial hypertension (PAH) (World Health Organization Group I), a subset of PH, and may be idiopathic in nature or associated with other systemic conditions and is thought to most commonly effect women, the majority of whom are of childbearing age. However, PAH in the elderly population is being increasingly diagnosed creating clinical considerations that had once not been considered. Often in an elderly population the diagnosis of PAH may be delayed due to chronic comorbid conditions such as coronary artery disease or other dyspneic conditions. Though survival and clinical outcomes have improved, the elderly population continues to have disproportionately lower survival rates. High clinical suspicion of $P A H$ warrants a complete diagnostic workup with right heart catheterization. Upon diagnosis, PAH specific therapy should be initiated with possible drug interactions in mind. Adjuvant pulmonary rehabilitation should be considered as a conservative measure with definitive results. Finally, psychosomatic aspects of the disease should also be considered in elderly populations. (Cardiol J 2020; 27, 2: 184-193)
\end{abstract}

Key words: pulmonary hypertension, pulmonary arterial hypertension, pulmonary hypertension in the elderly, geriatric medicine, pulmonary vascular disease

\section{Introduction}

Pulmonary hypertension $(\mathrm{PH})$ is a rare and devastating disease characterized by progressive increases in pulmonary arterial pressure and pulmonary vascular resistance, which eventually leads to right ventricular failure and death $[1,2]$. Pulmonary hypertension is defined hemodynamically as a mean resting pulmonary artery pressure (mPAP) greater than or equal to $25 \mathrm{mmHg}$ as confirmed by right heart catheterization (RHC). The World Health Organization (WHO) has proposed a classification system for $\mathrm{PH}$ based on common clinical features and etiology, which is outlined in
Table 1 [3]. Regardless of classification efforts, $\mathrm{PH}$ remains to be a clinical challenge due to its complex pathogenesis, limited disease specific therapies and healthcare disparities [4].

Pulmonary arterial hypertension (PAH) (WHO Group I PH), may be idiopathic in nature or associated with connective tissue diseases, congenital heart disease, portal hypertension, HIV or drug induced and is thought to most commonly effect women, the majority of whom are of childbearing age $[3,5,6]$. Due to disease recognition and readily available advanced diagnostic modalities, $\mathrm{PAH}$ in the elderly population is being increasingly diagnosed. Recent data has shown that there was

Address for correspondence: Sonu Sahni, MD, Touro College of Osteopathic Medicine, Department of Primary Care, 230 W 125th Street, New York, NY 10027, USA, tel: (646) 981-4507, fax: (212) 678-1784, e-mail: sahni.sonu@gmail.com Received: 27.12.2017 Accepted: 11.07.2018 
Table 1. World Health Organization Classification of Pulmonary Hypertension.

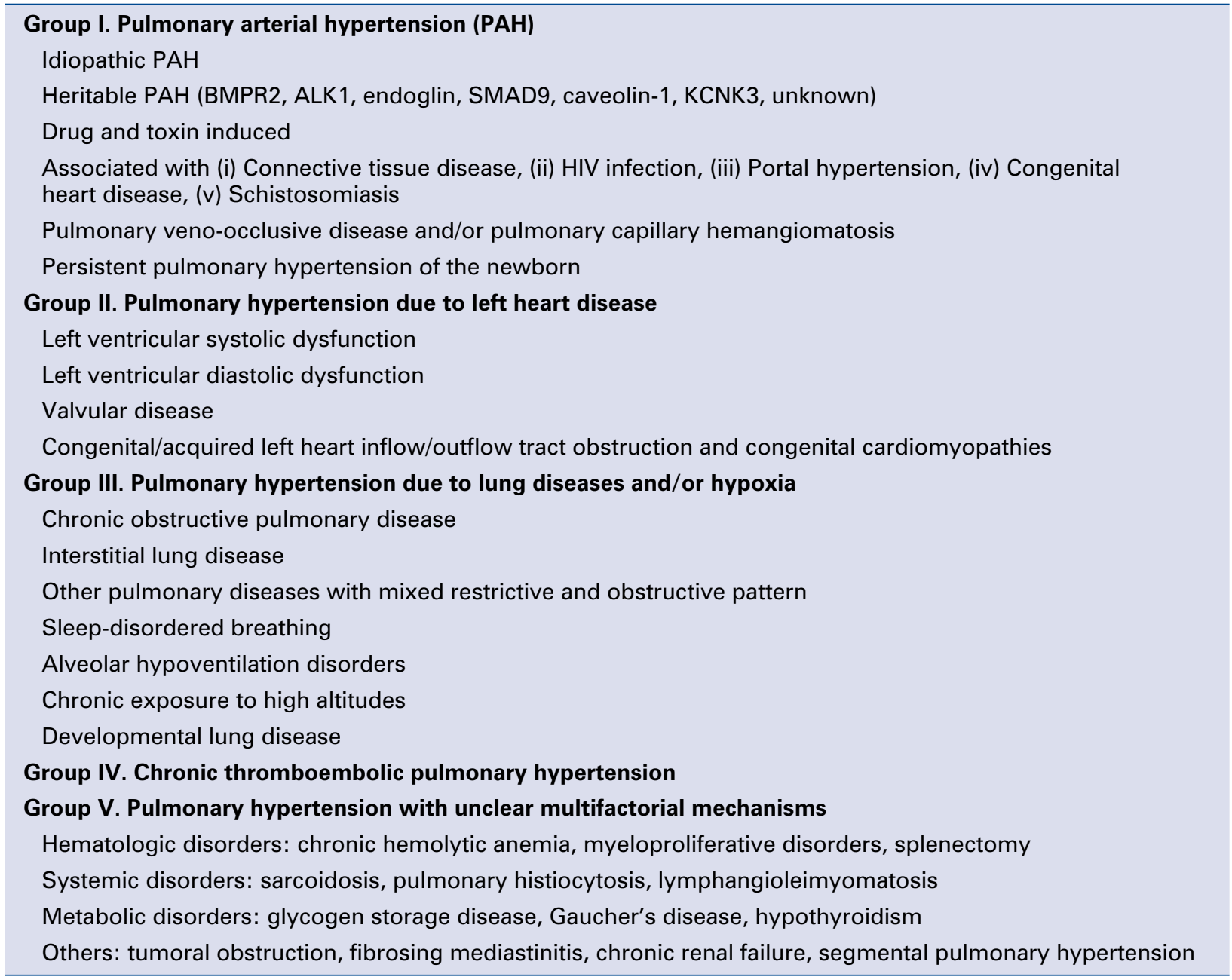

$5^{\text {th }}$ World Symposium on Pulmonary Hypertension, Nice, France 2013

BMPR - bone morphogenic protein receptor type II; HIV — human Immunodeficiency

a shift in the demographics of PAH with initial diagnosis coming at an older age, creating clinical considerations once not thought of $[7,8]$. Though the underlying causes of PAH are well studied, in the elderly it presents a clinical challenge to the standard therapeutic algorithm. This review article will serve to describe the changing epidemiology and challenges clinicians face in the diagnosis and management of $\mathrm{PAH}$ in the elderly population.

\section{Methods}

A comprehensive literature search was conducted of the National Library of Medicine's MEDLINE/PubMed with the objective of identifying all articles published in the English language between January 1980 and May 2018 with "elderly" and "pulmonary arterial hypertension" in the title. Combinations of medical subject heading terms including "pulmonary arterial hypertension," "changes with age" and "management of pulmonary hypertension in the elderly" were used. Recent publications were mainly selected, but older works were not excluded provided that they were widely referenced. Reference lists were also searched of all articles identified by this search strategy and those that were judged to be relevant were also selected. All pertinent reports were retrieved and the relative reference lists were systematically searched in order to identify any potential additional studies that could be included. All data were accessed between January 2017 and May 2018.

\section{General considerations}

Pulmonary arterial hypertension is characterized by a specific pattern on pulmonary hemodynamics. During RHC, there is an added criterion 
of pulmonary capillary wedge pressure (PCWP) $\leq 15 \mathrm{mmHg}$ with an absolute increase in pulmonary vascular resistance (PVR) ( $>3 \mathrm{WU})$, and is labeled as pre-capillary PH [9]. Histologically, this group of conditions is characterized by vascular specific changes such as endothelial and fibroblast dysfunction. These molecular level changes affect different pathways implicated in the specific therapy of PAH. Among them are the nitric oxide, endothelin and prostacyclin pathways.

The health care burden of PH has also increased in the recent decades [10]. Secondary causes of $\mathrm{PH}$ are the still the most common in the elderly population such as $\mathrm{PH}$ due to left heart disease (WHO Group $2 \mathrm{PH}$ ) and $\mathrm{PH}$ due to lung disease/hypoxia (WHO Group $3 \mathrm{PH}$ ) [11]. The incidence of $\mathrm{PH}$ with heart failure with preserved ejection fraction (HFpEF) was noted to be between $36 \%$ to $83 \%$ based on recent studies [12-14]. In contrast to pre-capillary PH (PAH), left heart disease causes post-capillary $\mathrm{PH}$ secondary to backward transmission of elevated left-sided filling pressures into the pulmonary circulation. These patients may demonstrate either isolated postcapillary $\mathrm{PH}$ or combined post-capillary $\mathrm{PH}$ along with a component of pre-capillary $\mathrm{PH}$. In these patients, invasive hemodynamics show a combination of elevated PCWP and increased PVR [9]. Thus, despite the presence of clear definitions an increasing number of patients are noted to have simultaneous existence of multiple categories of $\mathrm{PH}$. This is especially relevant in the elderly population who have a have increased co-morbidities associated with $\mathrm{HFpEF}$ such has arterial hypertension, atrial fibrillation and age related diastolic dysfunction.

Pulmonary arterial hypertension remains a relatively rare diagnosis in the elderly as well as WHO Group IV, chronic thromboembolic PH (CTEPH) [15]. In the elderly, management of PH due to secondary causes is dictated by the etiology and disease severity. Diagnosis in the elderly is often elusive due to non-specific findings including shortness of breath, fatigue, weakness, angina and syncope; these symptoms are largely due to right ventricular dysfunction [9]. In a study by Shapiro et al. [16] examining unexplained PH in the elderly population it was found that despite in the absence of secondary causes of $\mathrm{PH}$ the elderly population did not meet the diagnostic hemodynamic criteria for PAH due to elevated PCWP [16]. A strong clinical suspicion and complete diagnostic workup including a RHC should be considered if $\mathrm{PAH}$ is in the differential.

\section{Epidemiology}

Traditionally it has been thought that PAH is a disease of the young, however, studies have shown that the number of elderly patients (age $\geq 65$ years) being diagnosed with PAH is increasing. United States registry data suggests that PAH has an older age at diagnosis as compared with the $\mathrm{Na}$ tional Institute of Heath registry study performed in the 1980s, with nearly $17 \%$ of the cohort 65 years of age at the time of diagnosis in the last decade [17-19]. A multinational European registry has found that up to $63 \%$ of patients in a cohort of $\mathrm{PAH}$ were aged 65 years or older [8]. Baseline characteristics of $\mathrm{PAH}$ patients across various registries has been outlined in Table 2 [7, 8, 18-23].

There appears to be a trend of diagnosis of PAH occurring at a later age (Fig. 1). In the latest epidemiological registry results, it was found by Mueller-Mottet et al. [23] that since 2000, the age of Swiss PAH patients has been gradually getting older. A study by Hoeper et al. [8], the Comparative, Prospective Registry of Newly Initiated Therapies for Pulmonary Hypertension (COMPERA) revealed the highest median age $(71 \pm 16$ years) at diagnosis was reported in the literature with a majority of patients being of the elderly population. The Registry to Evaluate Early And Long-term PAH Disease Management (REVEAL) found that being a male greater than 60 years of age showed an increased risk of mortality [24]. This observed trend may due to various reasons including delay in diagnosis as it is known that the mean duration between symptom onset and diagnostic catheterization has been reported to be approximately 2.8 years [18]. In the elderly population, this may hold especially true due to the rare nature of the disease and presence of other comorbid dyspneic conditions such as chronic obstructive pulmonary disease (COPD) and coronary artery disease (CAD). In a study by Shimony et al. [25] it was found that in the cohort of patients age 65 and older there was a 4.6 times greater prevalence of significant $\mathrm{CAD}$ than those individuals less than age 65, which may lead to dyspnea and further delay the diagnosis of PAH. Delays in diagnosis may be detrimental as elderly patients tend to present at a worse functional class, which may due to their underlying comorbidities or even extrinsic factors such as socioeconomic status [26, 27].

\section{Diagnostic considerations}

The diagnosis of $\mathrm{PH}$ requires a high degree of clinical suspicion based on symptoms and physical 
Table 2. Baseline epidemiologic characteristics of pulmonary arterial hypertension registries.

\begin{tabular}{lcccccccc}
\hline Registry & NIH & French & US & REVEAL & UK/Ireland & ASPIRE COMPERA Swiss \\
\hline Year & 1987 & 2006 & 2007 & 2010 & 2012 & 2012 & 2013 & 2015 \\
Number & 187 & 674 & 578 & 2525 & 482 & 175 & 587 & 171 \\
Mean age at diagnosis [years] & $36 \pm 15$ & $50 \pm 15$ & $48 \pm 14$ & $50.1 \pm 14.4$ & $50.1 \pm 17.1$ & $55 \pm 16$ & $71 \pm 16$ & $60 \pm 15$ \\
Women [\%] & 63.0 & 65.3 & 77.0 & 55.6 & 69.9 & 67.0 & 60.3 & 56.0 \\
\hline
\end{tabular}

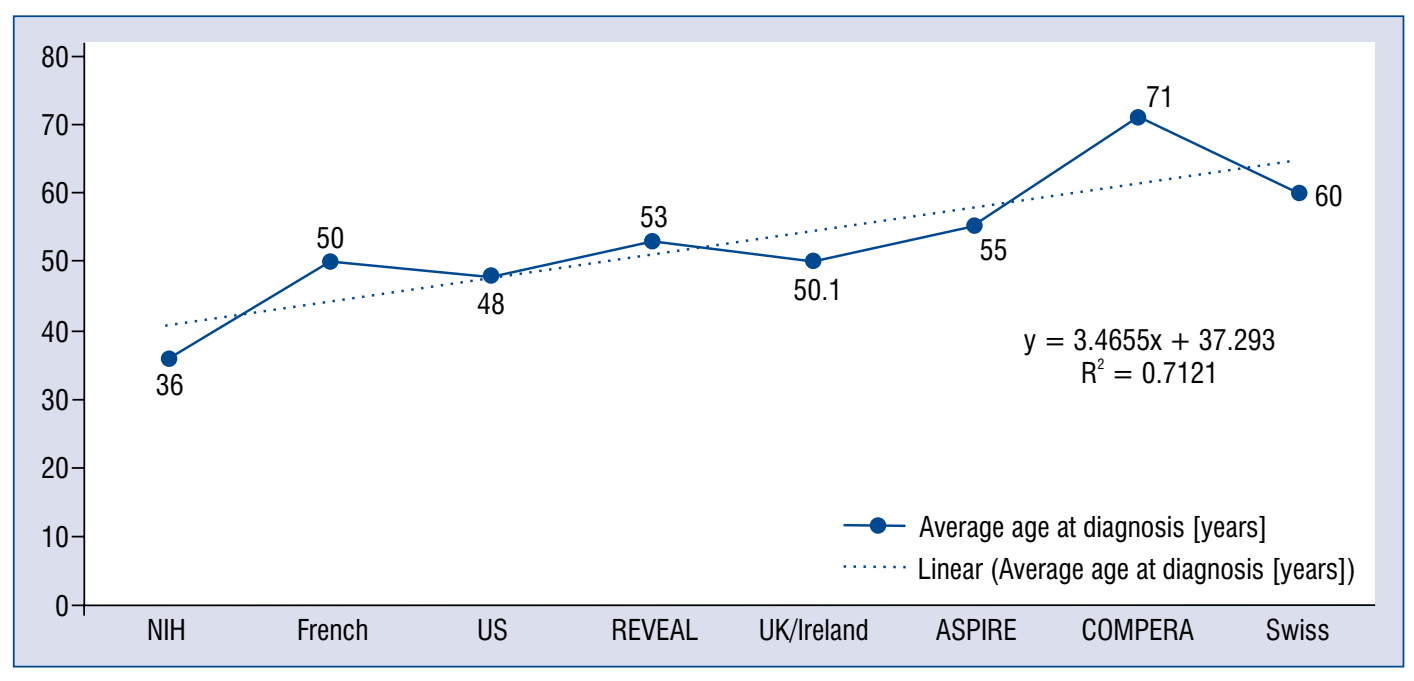

Figure 1. Chronological display of average age of diagnosis in pulmonary arterial hypertension registries.

examination. This is followed by a comprehensive set of investigations to assess the hemodynamics as well as to determine the etiology of the disease process. Basic work up includes electrocardiogram, chest radiograph, pulmonary function tests, 6-minute walk distance (6MWD), arterial blood gas, echocardiography, ventilation/perfusion scan and high-resolution computed tomography [6]. It is also important to assess for left atrial pressures to rule out Group II PH. Pressure measurements include PAP measurements and PCWP as a surrogate of left atrial pressure. Derived variables include calculating a PVR and transpulmonary pressure gradient (TPG). A PVR $>3 \mathrm{WU}$ is required for diagnosis of PAH. TPG is calculated as the difference between mPAP and PCWP and has been used to distinguish 'passive' PH (TPG < $12 \mathrm{mmHg}$ ) from 'reactive' PH (TPG $\geq 12 \mathrm{mmHg}$ ). Unfortunately, the limitation of this measurement is that it is influenced by multiple determinants of mPAP including flow, resistance and left heart filling pressures. Diastolic $\mathrm{PAP}$ on the other hand is less influenced by PCWP at any level of stroke volume. Therefore the 2015 $\mathrm{PH}$ guidelines recommends diastolic pulmonary gradient (DPG) defined as diastolic PAP - mean PCWP as the best approach to determine the presence of pulmonary vascular disease. Thus in a patient with $\mathrm{mPAP} \geq 25 \mathrm{mmHg}$ and $\mathrm{PCWP}$ $>15 \mathrm{mmHg}$, a DPG $<7 \mathrm{mmHg}$ and/or PVR $\leq 3 \mathrm{WU}$ reflects the presence of isolated post-capillary $\mathrm{PH}$ while a DPG $\geq 7 \mathrm{mmHg}$ and/or PVR $>3$ WU represents combined post-capillary and pre-capillary $\mathrm{PH}$.

Pulmonary vasoreactivity testing during the RHC is also considered for patients with PAH. A positive response is defined as reduction of $\mathrm{MPAP}$ $>10 \mathrm{mmHg}$ to reach an absolute value of mPAP of $\leq 40 \mathrm{mmHg}$ with an increased unchanged cardiac output. Coronary angiography should be considered in patients with risk factors of $\mathrm{CAD}$ or in patients being listed for pulmonary endarterectomy or lung transplantation [28].

\section{Management}

At present curative options for PAH are limited to lung transplantation which in the elderly has shown to carry an increased risk of mortality [29]. However, over the past decade targeted pharmaceutical options have become available 
Table 3. Medications in the management of pulmonary arterial hypertension (PAH).

\begin{tabular}{ll}
\hline PAH specific therapies & Mode of administration \\
\hline Phosphodiesterase type-5 (PDE) inhibitors & Oral \\
Sildenafil (Revatio) & Oral \\
Tadalafil (Adcirca) & \\
Prostacyclin analogues & Intravenous infusion, injection \\
Epoprostenol (Flolan, Valetri) & Intravenous infusion, inhalation, oral \\
Treprostinil (Remodulin, Tyvaso, Orenitram) & Inhalation \\
lloprost (Ventavis) & \\
Prostacyclin receptor agonist & Oral \\
Selexipag (Uptravi) & \\
Endothelin receptor antogonists (ERAs) & Oral \\
Bosentan (Tracleer) & Oral \\
Ambrisentan (Letairis, Volibris) & Oral \\
Macitentan (Opsumit) & \\
Soluble guanylate cyclase (sGC) stimulator & Oral \\
Riociguat (Adempas) & \\
\hline
\end{tabular}

for the treatment of PAH (Table 3) [9, 30]. There are different classes of medications available with different mechanisms of actions, all of which net a vasodilatory and anti-proliferative effect $[9,30]$. If $\mathrm{PH}$ is suspected all efforts must be made to exclude secondary causes. Once a definitive diagnosis of PAH has been made with RHC, drug specific therapy should be initiated. Certain considerations should be observed in this population relating to therapeutic response. In general, elderly patients are weaker responders to vasodilatory effects which may due to age related vascular stiffening of the pulmonary arteries. It has been shown that a significant age-related increase in pulmonary artery systolic pressure exists and increases about $1 \mathrm{mmHg}$ annually [31,32]. Additional special considerations need to be taken in the geriatric population while using PAH specific therapy. These considerations set forth by the Food and Drug Administration have been outlined in Table 4 [33].

Pharmacotherapy of PAH should be addressed in a cautious way. A majority of patients of the elderly age group diagnosed with $\mathrm{PAH}$ also tend to have underlying chronic comorbidities. In the United Kingdom PAH registry, it was found that in patients greater than age 50 , nearly all patients suffered from systemic hypertension, more than half from diabetes as well as ischemic heart disease [7]. These patients should have their co-morbid conditions managed optimally to reduce the synergistic effects on PAH.

In the elderly population, delayed diagnosis usually means advanced disease at presentation.
With evidence pointing towards initial combination therapy, the use of multiple drugs working on multiple PAH pathways creates the possibility of drug-drug interactions in the elderly population. The phosphodiesterase type- 5 sildenafil is metabolized via the cytochrome $\mathrm{P} 450$ pathway specifically involving CYP3A4 and CYP2C9. There is an increase in sildenafil bioavailability and reduced clearance with CYP3A4 substrates and inhibitors and CYP3A4 substrates plus beta-adrenoceptor blockers. Drugs that are CYP3A4 inducers such as barbiturates, rifampicin and St. John's wort may lower sildenafil levels and should be used with caution. Sildenafil levels are modestly increased by fresh grapefruit juice, a weak inhibitor of CYP3A4 [34].

The endothelin receptor antagonists bosentan is an inducer of cytochrome P450 isoenzymes CYP3A4 and CYP2C9. Plasma concentrations of drugs metabolized by these isoenzymes will be reduced when co-administered with bosentan. Of note is that the combination of a potent CYP3A4 inhibitor (ketoconazole, ritonavir) and/or a CYP2C9 inhibitor (e.g. amiodarone, fluconazole) with bosentan may cause a significant increase in plasma bosentan levels and thus is contraindicated. Interactions may theoretically occur with certain antifungals as well as immunosuppressive drugs. It is also important to note that bosentan is often administered concomitantly with sildenafil as part of dual PAH therapy. It has been found that bosentan significantly decreases the plasma concentration 
Table 4. Geriatric considerations of select pulmonary arterial hypertension specific medications.

\begin{tabular}{|c|c|}
\hline Drug & Geriatric consideration \\
\hline Sildenafil & $\begin{array}{l}\text { - Clinical studies of did not include sufficient numbers of subjects aged } 65 \text { and over } \\
\text { to determine whether they respond differently from younger subjects. Other reported } \\
\text { clinical experience has not identified differences in responses between the elderly } \\
\text { and younger patients. }\end{array}$ \\
\hline Tadalafil & $\begin{array}{l}\text { - No overall differences in safety were observed between subjects over } 65 \text { years } \\
\text { of age compared to younger subjects or those over } 75 \text { years of age. }\end{array}$ \\
\hline Riociguat & $\begin{array}{l}\text { - No overall differences in safety or effectiveness were observed between elderly } \\
\text { and younger subjects. }\end{array}$ \\
\hline Bosentan & - No conclusive evidence from clinical trials. \\
\hline \multirow[t]{3}{*}{ Ambrisentan } & $\begin{array}{l}\text { - The elderly (age } \geq 65 \text { years) showed less improvement in walk distances with Letairis } \\
\text { than younger patients did. Peripheral edema was more common in the elderly than } \\
\text { in younger patients. }\end{array}$ \\
\hline & $\begin{array}{l}\text { - Improvements in walk distance with Letairis were smaller for elderly patients } \\
\text { (age } \geq 65) \text { than younger patients. }\end{array}$ \\
\hline & $\begin{array}{l}\text { - Peripheral edema was greater in elderly patients (age } \geq 65 \text { ) receiving Letairis as } \\
\text { compared to placebo. }\end{array}$ \\
\hline Mactitentan & $\begin{array}{l}\text { - No overall differences in safety or effectiveness were observed between these } \\
\text { subjects and younger subjects. }\end{array}$ \\
\hline $\begin{array}{l}\text { Epoprostenol/iloprost/ } \\
\text { /treprostinil }\end{array}$ & $\begin{array}{l}\text { - No conclusive evidence from clinical trials or clinical experience. In general, dose } \\
\text { selection for an elderly patient should be cautious, usually starting at the low end } \\
\text { of the dosing range, reflecting the greater frequency of decreased hepatic, renal, } \\
\text { or cardiac function and of concomitant disease or other drug therapy. }\end{array}$ \\
\hline Selexipag & $\begin{array}{l}\text { - No overall differences were observed between these subjects and younger subjects, } \\
\text { and other reported clinical experience has not identified differences in responses } \\
\text { between the elderly and younger patients }\end{array}$ \\
\hline
\end{tabular}

All considerations obtained from Federal Drug Administration (FDA) drug approved package inserts.

of sildenafil when co-administered to patients with PH [35]. A detailed outline of PAH specific medications and interactions with commonly used drugs is shown in Table 5 [36].

Currently there are no guidelines on treatment of PAH specifically in the elderly. Treatment of PAH is dictated by WHO functional class at presentation $[9,30]$. However there has been a trend towards the use of oral medications such as bosentan over intravenous or inhalation prostacyclins, possibly due to the ease of use and compliance [25]. In addition, it has been observed that there is a tendency to use monotherapy in the elderly as observed in the COMPERA trial as well as in the United Kingdom population [8].

Another aspect to consider in pharmacotherapy treatment of elderly patients diagnosed with $\mathrm{PAH}$ is the presence of risk factors for concurrent left heart disease. Several registries have documented a change in phenotype of patients with PAH with increasing age $[7,8]$. The terms typical and atypical PAH have been proposed to distinguish between these two populations [12]. Opitz et al. [12] in their review of the COMPERA trial, noted that patients with atypical PAH share features of both typical PAH and PH-HFpEF indicating that there might be a continuum between these conditions. Multiple studies have demonstrated that these patients with risk factors of left heart disease presenting with pre-capillary PH (atypical PAH) may benefit from targeted therapies [12, 28, 37, 38]. Opitz et al. [12] also demonstrated the potential benefits of targeted $\mathrm{PH}$ therapies in patients with $\mathrm{HFpEF}$ and combined post-capillary and pre-capillary $\mathrm{PH}$.

Thus, future studies are warranted to identify treatment strategies for this patient population. This is especially important in the elderly population, as there is a growing number of $\mathrm{PH}-\mathrm{HFpEF}$ patients diagnosed as $\mathrm{PAH}$, and the efficacy of specific PAH therapy may decline and side effects may become more prominent.

\section{Pulmonary rehabilitation}

Pulmonary rehabilitation (PR) is defined as a comprehensive intervention based on a thorough patient assessment followed by patient-tailored therapies, which include, but are not limited to, 


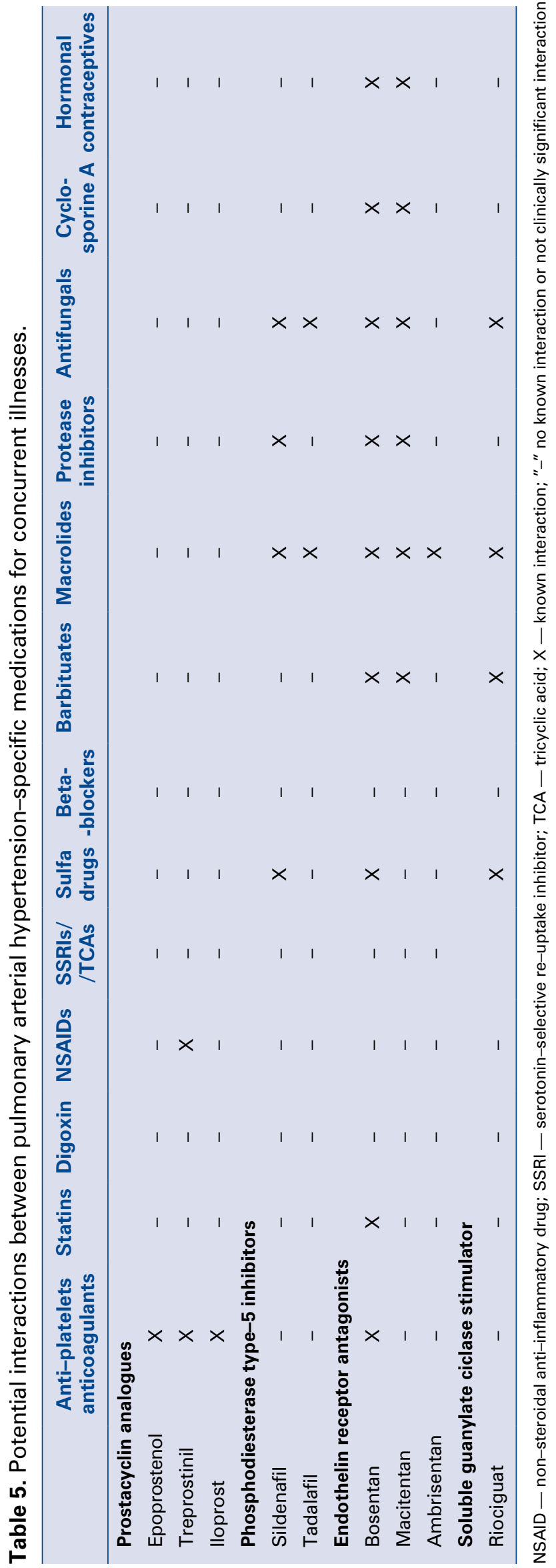

exercise training, education, and behavior change, all designed to improve the physical and psychological condition of people with chronic respiratory disease and to promote long-term adherence of health-enhancing behaviors [39]. The primary goal of PR programs is to improve function, disease related symptoms, optimize functional capacity and an overall improvement in quality of life (QoL) [40]. A multinational European study by Spruit et al. [41] found that there are still large differences among PR programs across continents. Their findings stress the importance of future development of processes and performance metrics to monitor $\mathrm{PR}$ programs to begin standardization, and to provide recommendations for internationally evidence based guidelines.

Pulmonary rehabilitation has been well-studied and has been demonstrated to reduce dyspnea, increase exercise tolerance and improve healthrelated QoL in patients with COPD and idiopathic pulmonary fibrosis in the elderly [39, 42, 43]. While there are fewer trials of PR in patients with $\mathrm{PAH}$, they also show that PR improves exercise capacity, muscle strength and health-related QoL [44]. A recent study by Talwar et al. [45] has shown that patients across all groups of pulmonary hypertension with an average age of $67.7 \pm 11.6$ years there was improvement in exercise tolerance as measured by miles per hour. Being that PR is a conservative treatment, philosophy dictates consideration in pharmacologically optimized PAH patients, utilization in the elderly population may be beneficial. It may also be beneficial in patients who have been deemed unable to receive pharmacotherapy. Though these small trials have provided beneficence in an elderly population, certain precautions must be taken prior to initiation, including a pulmonary and cardiac clearance.

Several studies have also found that PR improves numerous clinical endpoints. Mereles et al. [46], found that 30 patients with either idiopathic PAH or CTEPH experienced improvements in 6MWD and QoL self-assessment scores; importantly, rehabilitation was well-tolerated and deemed to be safe. Another study found an improvement in $6 \mathrm{MWD}$, resting heart rate, peak oxygen consumption, oxygen saturation and systolic pulmonary artery pressure in patients with $\mathrm{PH}$ due to connective tissue disease [47]. Though these study cohorts were not exclusively elderly patients it may be inferred that they provide a similar benefit.

\section{Psychosomatic considerations}

Pulmonary arterial hypertension is a debilitating lung disease characterized exertional dyspnea, 
exercise intolerance, palpitations, fatigue and even syncope. Besides the somatic effects of the disease the elderly population is more averse to the psychological effects of the disease. In the elderly population where disease severity may be at a peak or pharmacotherapy contraindicated, improving psychosomatic manifestations of the disease may be the only option. Assessing psychological and somatic effects of the disease may be difficult, however with the use of a standardized instrument may be advantageous. Recently the PAH-SYMPACT questionnaire demonstrated to be a valid patient self-reporting tool to measure the impact that PAH is having on an individual [48].

It has been well documented that depression and diminished mental functioning are part of the PAH picture [40, 49]. In addition, diseasespecific symptoms such as shortness of breath can adversely affect health related QoL (HRQoL), increase anxiety and be independently related to depression [50-52]. HRQoL in patients with PAH has been shown to be correlated with 6MWD and may affect WHO functional class status [52]. Worsening HRQoL and depressive symptoms may result in a decrease in physical activity, which reduces exercise tolerance and worsens dyspnea - this notion is supported by evidence that exercise and PR has been demonstrated to improve exercise capacity and WHO functional class [47, 53]. As noted above, dyspnea is independently related to depressive symptoms; another study that patient self-reported dyspnea negatively correlates with a reduced mental and physical QoL [40]. Taken together, the evidence supports the possibility of a "vicious cycle" of worsening dyspnea resulting in decreased exercise tolerance and worsening depressive symptoms, leading to decreased HRQOL which then decreases physical activity further, perpetuating the cycle as the disease progresses.

Considerations of the relationship between dyspnea, HRQoL and depression are of particular note in the elderly as depression is already a significant problem in this population: $5 \%$ of communitydwelling older adults suffer from major depressive disorder and $8 \%$ to $16 \%$ of older adults have clinically significant depressive symptoms [54]. Furthermore, rates of major depressive disorder rise as medical morbidity increases. Jackson et al. [55] found that up to $37 \%$ of patients suffer from major depressive disorder after critical care hospitalizations. Therefore, it is important for practitioners to recognize depression in elderly patients with $\mathrm{PH}$ and provide appropriate interventions.
Another psychosomatic aspect of PAH, often overlooked, in the elderly is fatigue. Fatigue is defined as extreme, persistent tiredness and mental, physical weakness or exhaustion and represents a psychosomatic domain of the disease [56, 57]. In the setting of $\mathrm{PH}$ fatigue may have a multifactorial etiology, including many conditions that can underlie $\mathrm{PH}$ or be associated with $\mathrm{PH}$ such as heart failure, obstructive sleep apnea, depression, muscle weakness and osteoporosis, so recognition and effective treatment of other contributing factors is important [58]. The studies of fatigue in PAH are rare, however in a study by Sahni et al. [59] a cohort of 42 patients comprised of all WHO groups of PH, there was an elevated level of fatigue as measured by the fatigue severity scale. In an another study, Talwar et al. [58] found that in a cohort of 21 patients with a mean age 64.3 years with advanced lung disease (COPD and interstitial lung disease) there was an elevated level of fatigue as measured by the Fatigue Severity Scale and also an improvement in fatigue symptoms after completion of a PR program.

\section{Survival}

Over the past decades, with the advent of PAH specific drugs, in general the outcomes of PAH have improved [60]. However, the elderly cohort is unique in that survival of PAH patients is not as favorable as in younger populations, which may be multifactorial. In an analysis of 587 patients from the COMPERA registry all-cause mortality was $18.4 \%$. There were 108 deaths; 25 (mortality rate, $12.0 \%$ ) in the younger cohort ( $<65$ years of age) and 83 (mortality rate, $22.0 \%$ ) in the older one $(\mathrm{p}=0.003)$ and in younger patients, the 1-, 2-, and 3-year survival rates were $96.0 \%, 90.9 \%$ and $83.3 \%$, respectively. The corresponding survival rates in the older patients were $89.8 \%, 78.6 \%$ and $68.0 \%$ [8]. The authors attributed the lower survival rate in the elderly cohort to limited response to pharmacotherapy and a less aggressive approach relying on monotherapy over combination therapy. In a study that analyzed data from six randomized treatment trials patients were categorized into three age groups following traditional cut-offs $(\leq 50,50-65$, and $\geq 65$ years old). It was found though that mortality rates were generally lowacross the groups, there was a significantly higher rate of mortality as age groups increased, mortality rates were $16.6 \%, 24.6 \%$ and $28.6 \%$ in the three age groups, respectively $(\mathrm{p}=0.0004)[27]$. 


\section{Conclusions}

Pulmonary arterial hypertension in the elderly remains to be a rare diagnosis, however it is becoming more recognized. Often in an elderly population the diagnosis of PAH may be delayed due to chronic comorbid conditions such as CAD or other dyspneic conditions. Though survival and clinical outcomes have improved, the elderly population continues to have disproportionately lower survival rates. A high clinical suspicion of PAH warrants a complete diagnostic workup with right heart catheterization. Upon diagnosis of PAH, specific therapy should be initiated with possible drug interaction in mind. Adjuvant PR should be considered as a conservative measure with definitive results. Finally, psychosomatic aspects of the disease should also be considered in an elderly population.

\section{Conflict of interest: None declared}

\section{References}

1. Farber HW, Loscalzo J. Pulmonary arterial hypertension. N Engl J Med. 2004; 351(16): 1655-1665, doi: 10.1056/NEJMra035488, indexed in Pubmed: 15483284 .

2. Badesch DB, Champion HC, Sanchez MA, et al. Diagnosis and assessment of pulmonary arterial hypertension. J Am Coll Cardiol. 2009; 54(1 Suppl): S55-S66, doi: 10.1016/j.jacc.2009.04.011, indexed in Pubmed: 19555859.

3. Simonneau G, Gatzoulis MA, Adatia I, et al. Updated clinical classification of pulmonary hypertension. J Am Coll Cardiol. 2013; 62(25 Suppl): D34-D41, doi: 10.1016/j.jacc.2013.10.029, indexed in Pubmed: 24355639.

4. Talwar A, Garcia JGN, Tsai H, et al. Health disparities in patients with pulmonary arterial hypertension: a blueprint for action. An official american thoracic society statement. Am J Respir Crit Care Med. 2017; 196(8): e32-e47, doi: 10.1164/rccm.2017091821ST, indexed in Pubmed: 29028375.

5. McGoon MD, Miller DP. REVEAL: a contemporary US pulmonary arterial hypertension registry. Eur Respir Rev. 2012; 21(123): 8-18, doi: 10.1183/09059180.00008211, indexed in Pubmed: 22379169.

6. Athanasiou KA, Sahni S, Rana A, et al. Diagnosing and managing scleroderma-related pulmonary arterial hypertension. JAAPA. 2017; 30(9): 11-18, doi: 10.1097/01.JAA.0000522129.93995.13, indexed in Pubmed: 28858011.

7. Ling Yi, Johnson MK, Kiely DG, et al. Changing demographics, epidemiology, and survival of incident pulmonary arterial hypertension: results from the pulmonary hypertension registry of the United Kingdom and Ireland. Am J Respir Crit Care Med. 2012; 186(8): 790-796, doi: 10.1164/rccm.201203-03830C, indexed in Pubmed: 22798320.

8. Hoeper M, Huscher D, Ghofrani H, et al. Elderly patients diagnosed with idiopathic pulmonary arterial hypertension: Results from the COMPERA registry. Int J Cardiol. 2013; 168(2): 871-880, doi: 10.1016/j.ijcard.2012.10.026.

9. Galie N, Humbert M, Vachiery JL, et al. 2015 ESC/ERS Guidelines for the diagnosis and treatment of pulmonary hypertension: The Joint Task Force for the Diagnosis and Treatment of Pulmonary Hypertension of the European Society of Cardiology
(ESC) and the European Respiratory Society (ERS): Endorsed by: Association for European Paediatric and Congenital Cardiology (AEPC), International Society for Heart and Lung Transplantation (ISHLT). Eur Heart J. 2016; 37(1): 67-119.

10. Sikachi RR, Sahni S, Mehta D, et al. Nationwide trends in inpatient admissions of pulmonary hypertension in the United States from 2000 to 2013. Adv Respir Med. 2017; 85(2): 77-86, doi: 10.5603/ARM.2017.0014, indexed in Pubmed: 28440533.

11. Guazzi M, Arena R. Pulmonary hypertension with leftsided heart disease. Nat Rev Cardiol. 2010; 7(11): 648-659 doi: 10.1038/nrcardio.2010.144, indexed in Pubmed: 20924360.

12. Opitz CF, Hoeper MM, Gibbs JS, et al. Pre-Capillary, combined, and post-capillary pulmonary hypertension: a pathophysiological continuum. J Am Coll Cardiol. 2016; 68(4): 368-378, doi: 10.1016/j.jacc.2016.05.047, indexed in Pubmed: 27443433.

13. Lam CSP, Roger VL, Rodeheffer RJ, et al. Pulmonary hypertension in heart failure with preserved ejection fraction: a community-based study. J Am Coll Cardiol. 2009; 53(13): 1119-1126, doi: 10.1016/j.jacc.2008.11.051, indexed in Pubmed: 19324256.

14. Leung CC, Moondra V, Catherwood E, et al. Prevalence and risk factors of pulmonary hypertension in patients with elevated pulmonary venous pressure and preserved ejection fraction. Am J Cardiol. 2010; 106(2): 284-286, doi: 10.1016/j.amjcard.2010.02.039, indexed in Pubmed: 20599017.

15. Pugh ME, Sivarajan L, Wang Li, et al. Causes of pulmonary hypertension in the elderly. Chest. 2014; 146(1): 159-166, doi: 10.1378/chest.13-1900, indexed in Pubmed: 24480915.

16. Shapiro BP, McGoon MD, Redfield MM. Unexplained pulmonary hypertension in elderly patients. Chest. 2007; 131(1): 94-100, doi: 10.1378/chest.06-1571, indexed in Pubmed: 17218561.

17. Frost AE, Badesch DB, Barst RJ, et al. The changing picture of patients with pulmonary arterial hypertension in the United States: how REVEAL differs from historic and non-US Contemporary Registries. Chest. 2011; 139(1): 128-137, doi: 10.1378/ chest.10-0075, indexed in Pubmed: 20558556.

18. Badesch DB, Raskob GE, Elliott CG, et al. Pulmonary arterial hypertension: baseline characteristics from the REVEAL Registry. Chest. 2010; 137(2): 376-387, doi: 10.1378/chest.09-1140, indexed in Pubmed: 19837821.

19. Rich S, Dantzker DR, Ayres SM, et al. Primary pulmonary hypertension. A national prospective study. Ann Intern Med. 1987; 107(2): 216-223, indexed in Pubmed: 3605900.

20. Humbert M, Sitbon O, Chaouat A, et al. Pulmonary arterial hypertension in France: results from a national registry. Am J Respir Crit Care Med. 2006; 173(9): 1023-1030, doi: 10.1164/ rccm.200510-16680C, indexed in Pubmed: 16456139.

21. Thenappan T, Shah SJ, Rich S, et al. A USA-based registry for pulmonary arterial hypertension: 1982-2006. Eur Respir J. 2007; 30(6): 1103-1110, doi: 10.1183/09031936.00042107, indexed in Pubmed: 17804449.

22. Hurdman J, Condliffe R, Elliot CA, et al. ASPIRE registry: assessing the Spectrum of Pulmonary hypertension Identified at a REferral centre. Eur Respir J. 2012; 39(4): 945-955, doi: 10.1183/09031936.00078411, indexed in Pubmed: 21885399.

23. Mueller-Mottet S, Stricker H, Domenighetti G, et al. Long-term data from the Swiss pulmonary hypertension registry. Respiration. 2015; 89(2): 127-140, doi: 10.1159/000370125, indexed in Pubmed: 25661477.

24. Raina A, Humbert M. Risk assessment in pulmonary arterial hypertension. Eur Respir Rev. 2016; 25(142): 390-398, doi: 10.1183/16000617.0077-2016, indexed in Pubmed: 27903661.

25. Shimony A, Fox BD, Afilalo J, et al. Pulmonary arterial hypertension in the elderly-clinical characteristics and long-term survival. Lung. 2012; 190(6): 645-649, doi: 10.1007/s00408-012-9425-5, indexed in Pubmed: 23064491.

26. Talwar A, Sahni S, Talwar A, et al. Socioeconomic status affects pulmonary hypertension disease severity at time of first 
evaluation. Pulm Circ. 2016; 6(2): 191-195, doi: 10.1086/686489, indexed in Pubmed: 27252845.

27. Omar AM, Jody MC, Adriano RT. Impact of Age on Pulmonary Arterial Hypertension Studies, in D25. Etiology and Determinants of Prognosis in Pulmonary Hypertension. A5502-A5502.

28. Galiè N, Barberà J, Frost A, et al. Initial Use of Ambrisentan plus Tadalafil in Pulmonary Arterial Hypertension. N Engl J Med. 2015; 373(9): 834-844, doi: 10.1056/nejmoa1413687.

29. Weiss ES, Merlo CA, Shah AS. Impact of advanced age in lung transplantation: an analysis of United Network for Organ Sharing data. J Am Coll Surg. 2009; 208(3): 400-409, doi: 10.1016/j. jamcollsurg.2008.12.010, indexed in Pubmed: 19318002.

30. Sahni S, Ojrzanowski M, Majewski S, et al. Pulmonary arterial hypertension: a current review of pharmacological management. Pneumonol Alergol Pol. 2016; 84(1): 47-61, doi: 10.5603/PiAP. a2015.0084, indexed in Pubmed: 26693827.

31. Lam CSP, Borlaug BA, Kane GC, et al. Age-associated increases in pulmonary artery systolic pressure in the general population. Circulation. 2009; 119(20): 2663-2670, doi: 10.1161/CIRCULATIONAHA.108.838698, indexed in Pubmed: 19433755.

32. Berra G, Noble S, Soccal PM, et al. Pulmonary hypertension in the elderly: a different disease? Breathe (Sheff). 2016; 12(1): 43-49, doi: 10.1183/20734735.003416, indexed in Pubmed: 27066136.

33. DAILYMED. 2017. https://dailymed.nlm.nih.gov/dailymed/ (2017 August 30th).

34. Ben-Dor I, Goldstein SA, Pichard AD, et al. Clinical profile, prognostic implication, and response to treatment of pulmonary hypertension in patients with severe aortic stenosis. Am J Cardiol. 2011; 107(7): 1046-1051, doi: 10.1016/j.amjcard.2010.11.031, indexed in Pubmed: 21296325.

35. Paul GA, Gibbs JS, Boobis AR, et al. Bosentan decreases the plasma concentration of sildenafil when coprescribed in pulmonary hypertension. Br J Clin Pharmacol. 2005; 60(1): 107-112, doi: 10.1111/j.1365-2125.2005.02383.x, indexed in Pubmed: 15963102 .

36. Ghofrani HA, Schermuly RT, Weissmann N, et al. Drug Interactions In Pulmonary Arterial Hypertension And Their Implications. US Cardiology Review. 2009; 6(2): 101-106.

37. Mclaughlin V, Galie N, et al. Barbera Galie JA, A Comparison of Characteristics and Outcomes of Patients with Atypical and Classical Pulmonary Arterial Hypertension from the AMBITION Trial. Am J Respir Crit Care Med. 2015; 191: A2196.

38. Charalampopoulos A, Howard LS, Tzoulaki I, et al. Response to pulmonary arterial hypertension drug therapies in patients with pulmonary arterial hypertension and cardiovascular risk factors. Pulm Circ. 2014; 4(4): 669-678, doi: 10.1086/678512, indexed in Pubmed: 25610602.

39. Spruit MA, Singh SJ, Garvey C, et al. An official American Thoracic Society/European Respiratory Society statement: key concepts and advances in pulmonary rehabilitation. Am J Respir Crit Care Med. 2013; 188(8): e13-e64, doi: 10.1164/rccm.2013091634ST, indexed in Pubmed: 24127811.

40. Talwar A, Sahni S, Kim EJi, et al. Dyspnea, depression and health related quality of life in pulmonary arterial hypertension patients. J Exerc Rehabil. 2015; 11(5): 259-265, doi: 10.12965/jer.150230, indexed in Pubmed: 26535216.

41. Spruit MA, Pitta F, Garvey C, et al. Differences in content and organisational aspects of pulmonary rehabilitation programmes. Eur Respir J. 2014; 43(5): 1326-1337, doi: 10.1183/09031936.00145613, indexed in Pubmed: 24337043.

42. Raghu G, Collard HR, Egan JJ, et al. An official ATS/ERS/JRS/ ALAT statement: idiopathic pulmonary fibrosis: evidence-based guidelines for diagnosis and management. Am J Respir Crit Care Med. 2011; 183(6): 788-824, doi: 10.1164/rccm.2009-040GL, indexed in Pubmed: 21471066.

43. Couser J, Guthmann R, Hamadeh M, et al. Pulmonary Rehabilitation Improves Exercise Capacity in Older Elderly Patients with COPD. Chest. 1995; 107(3): 730-734, doi: 10.1378/ chest.107.3.730.
44. Sahni S, Capozzi B, Iftikhar A, et al. Pulmonary rehabilitation and exercise in pulmonary arterial hypertension: An underutilized intervention. J Exerc Rehabil. 2015; 11(2): 74-79, doi: 10.12965/ jer.150190, indexed in Pubmed: 25960979.

45. Talwar A, Sahni S, Verma S, et al. Exercise tolerance improves after pulmonary rehabilitation in pulmonary hypertension patients. J Exerc Rehabil. 2017; 13(2): 214-217, doi: 10.12965/ jer.1732872.436, indexed in Pubmed: 28503536.

46. Mereles D, Ehlken N, Kreuscher S, et al. Exercise and respiratory training improve exercise capacity and quality of life in patients with severe chronic pulmonary hypertension. Circulation. 2006; 114(14): 1482-1489, doi: 10.1161/CIRCULATIONAHA.106.618397, indexed in Pubmed: 16982941.

47. Grünig E, Maier F, Ehlken N, et al. Exercise training in pulmonary arterial hypertension associated with connective tissue diseases. Arthritis Res Ther. 2012; 14(3): R148, doi: 10.1186/ ar3883, indexed in Pubmed: 22709477.

48. Chin KM, Gomberg-Maitland M, Channick RN, et al. Psychometric Validation of the Pulmonary Arterial HypertensionSymptoms and Impact (PAH-SYMPACT) Questionnaire: Results of the SYMPHONY Trial. Chest. 2018 [Epub ahead of print], doi: 10.1016/j.chest.2018.04.027, indexed in Pubmed: 29705220.

49. Verma S, Sahni S, Vijayan VK, et al. Depression in pulmonary arterial hypertension: An undertreated comorbidity. Lung India. 2016; 33(1): 58-63, doi: 10.4103/0970-2113.173072, indexed in Pubmed: 26933309 .

50. Kellner R, Samet J, Pathak D. Dyspnea, anxiety, and depression in chronic respiratory impairment. Gen Hosp Psychiatry. 1992; 14(1): 20-28, indexed in Pubmed: 1730397.

51. Löwe B, Gräfe K, Ufer C, et al. Anxiety and depression in patients with pulmonary hypertension. Psychosom Med. 2004; 66(6): 831-836, doi: 10.1097/01.psy.0000145593.37594.39, indexed in Pubmed: 15564346.

52. Taichman DB, Shin J, Hud L, et al. Health-related quality of life in patients with pulmonary arterial hypertension. Respir Res. 2005; 6: 92, doi: 10.1186/1465-9921-6-92, indexed in Pubmed: 16092961 .

53. Becker-Grünig T, Klose H, Ehlken N, et al. Efficacy of exercise training in pulmonary arterial hypertension associated with congenital heart disease. Int J Cardiol. 2013; 168(1): 375-381, doi: 10.1016/j.ijcard.2012.09.036, indexed in Pubmed: 23041100.

54. Blazer DG. Depression in late life: review and commentary. J Gerontol A Biol Sci Med Sci. 2003; 58(3): 249-265, indexed in Pubmed: 12634292.

55. Jackson JC, Pandharipande PP, Girard TD, et al. Depression, posttraumatic stress disorder, and functional disability in survivors of critical illness in the BRAIN-ICU study: a longitudinal cohort study. Lancet Respir Med. 2014; 2(5): 369-379, doi: 10.1016/ S2213-2600(14)70051-7, indexed in Pubmed: 24815803.

56. Krupp LB, LaRocca NG, Muir-Nash J, et al. The fatigue severity scale. Application to patients with multiple sclerosis and systemic lupus erythematosus. Arch Neurol. 1989; 46(10): 1121-1123, indexed in Pubmed: 2803071.

57. Pawlikowska T, Chalder T, Hirsch SR, et al. Population based study of fatigue and psychological distress. BMJ. 1994; 308(6931): 763-766, indexed in Pubmed: 7908238.

58. Talwar A, Sahni S, John S, et al. Effects of pulmonary rehabilitation on Fatigue Severity Scale in patients with lung disease. Pneumonol Alergol Pol. 2014; 82(6): 534-540, doi: 10.5603/ PiAP.2014.0070, indexed in Pubmed: 25339563.

59. Sahni S, Verma S, Singh K, et al. Fatigue in pulmonary hypertension patients. Chest. 2016; 150(4): 1163A, doi: 10.1016/j. chest.2016.08.1272.

60. Anand V, Roy SS, Archer SL, et al. Trends and Outcomes of Pulmonary Arterial Hypertension-Related Hospitalizations in the United States: Analysis of the Nationwide Inpatient Sample Database From 2001 Through 2012. JAMA Cardiol. 2016; 1(9): 1021-1029, doi: 10.1001/jamacardio.2016.3591, indexed in Pubmed: 27851838 . 